\title{
Geographic structure of the migrant labour market in China: A case study of four city-regions in Fujian
}

\author{
$\mathrm{Li} \mathrm{Yu}$ \\ Wei Xu ${ }^{1}$ \\ Yu Zhu \\ Liyue Lin
}

\begin{abstract}
This study attempts to examine how local migrant labour markets behave differently in regions with varying development levels and local economic characteristics, based on a 2009 migrant survey conducted in four case cities in Fujian province, China. The study reveals that earnings characteristics and the role of earnings determents vary greatly across geographic regions. Specifically, in the economically more developed region, the return to human capital is higher, the effect of primitive social networks is lower, and the effect of institutional and cultural barriers is weaker.
\end{abstract}

Keywords: migrant labour market, regional development, human capital, social network, bukou.

\section{Résumé}

On accorde dernièrement plus grande attention à la différenciation de l'espace économique et de son impact sur le travail migrant. Dans le contexte chinois, peu d'études se sont penchées sur les processus géographiques de la différenciation économique régionale des villes-régions et sur leur effet sur le marché du travail migrant. En analysant les données recueillies dans quatre villes étudiées de la province de Fujian en Chine en 2009, l'étude conclut que les caractéristiques du marché du travail migrant varient selon les conditions de développement économique régional, et surtout que les facteurs déterminant les gains contribuent de manière différente au travail migrant local selon le degré de développement économique régional. L'étude révèle que dans les régions, dont l'économie régionale est plus développée, le rendement du capital humain est plus élevé, l'effet du réseau social primitif est moindre et l'effet des obstacles institutionnels et culturels est plus faible.

Keywords: migrant labour market, regional development, human capital, social network, bukou.

\section{Introduction}

Over the last three decades, the incremental but persistent economic reforms and opening up have fundamentally transformed China from a planned economy to a market-oriented economy. During the course of the reforms, Chinese labour markets have been dramatically altered by changes

1. Corresponding author: Wei Xu, Prentice Research Affiliate, Prentice Institute for Global Population \& Economy, Department of Geography, University of Lethbridge, 4401 University Drive West, Lethbridge AB Canada T1K 3M4; email: wei.xu@uleth.ca. Li Yu, Department of Geography, University of Lethbridge; Yu Zhu, Center for Population and Development Research, School of Geography, Fujian Normal University, P.R. China; and Liyue Lin, Center for Population and Development Research, Fujian Normal University. 
Yu et al.: Geographic structure of the migrant labour market in China

in the social and economic conditions (Xie and Hannum 1996). The strictly controlled interregional population mobility was gradually eroded, and the divided rural-urban labour market unified. Since the beginning of the 1990s, rapid economic growth in coastal China has generated a tremendous amount of employment opportunities, attracting millions of rural migrant workers to move to and work in the coastal cities (Du et al. 2005). The sheer number of rural migrant labourers flooding into urban areas has produced and reproduced urban economic and social structures in contemporary China (Bao et al. 2002). While the contribution of migrant workers to urban economic growth is widely acknowledged as a "Chinese advantage," migrants are also often considered to be a disadvantaged social group, greatly separated from local urban residents and clustered at the lower end of urban labour market (Fan 2001; Liang 2001; Zhao 2005). Research into the differentiation within migrant groups and the factors affecting their labour market performance is needed to enhance an understanding of the social and economic structure of migrant labour markets in China.

Not only are the earnings of migrant workers differentiated greatly, but the structure of earnings determinants may vary as well. Many studies have been conducted to understand the income determinants of migrant workers in Chinese cities. Neoclassical economists have focused on the return on investment in human capital of migrants, and its variation between the migrant workers and other social groups (Lu and Song 2006; Fu and Ren 2010). Structuralists have highlighted the importance of wider institutional processes and emphasized the demand side of the labour market. They have pointed out the existence of labour market segmentation in coastal China and its effects on migrants (Fan 2003a; Xu et al. 2006; Knight and Yueh 2009). Behaviourists and new migration economists have attempted to investigate the effects of factors beyond the conventional earnings determinants by including cognitive, social capital, and family factors (Fan 2003a; Du et al. 2005; Yueh 2008). While the existing literature on the income determinants of migrant labourers has generated some understanding of how various factors are related to the earnings of migrant workers, migrant workers are often treated as a homogenous group in coastal cities only, and labour migration is viewed as one-way process between origins and destinations (Borjas and Stephen 1992; Chiquiar and Hanson 2005). There are debates, however, on the differentiated effects of income determinants on various groups of migrant workers, and how such effects vary across space (Zhao 2005).

This paper attempts to examine the roles of various factors in determining individual earnings in migrant labour markets, and to identify the differences in the contribution of earnings determinants to migrant earnings across different types of destination cities, based on a migrant survey in Fujian province in 2009. The following section provides an overview of China's migrant labour market, and reviews theories and insights in the literature on the factors shaping individual earnings in a labour market. The data sources and analytical methods are then discussed. The findings are first reported by a descriptive analysis of labour market performance of migrant workers in Fujian province and four prefectural cityregions, and then by discussing the results of earnings modelling. The paper is concluded by relating the findings of this paper to the debates in the literature on migrant labour markets in China.

\section{Perspectives on Chinese migrant labour markets}

\section{Rural-urban migration and migrant labour markets in China}

The strict labour mobility control in China started to be relaxed at the beginning of the reforms initiated in 1978 (Ma 2002). While the bukou system that binds people and place together with an official residency registration requirement still exists, the mobility-constraining effects of the bukou 


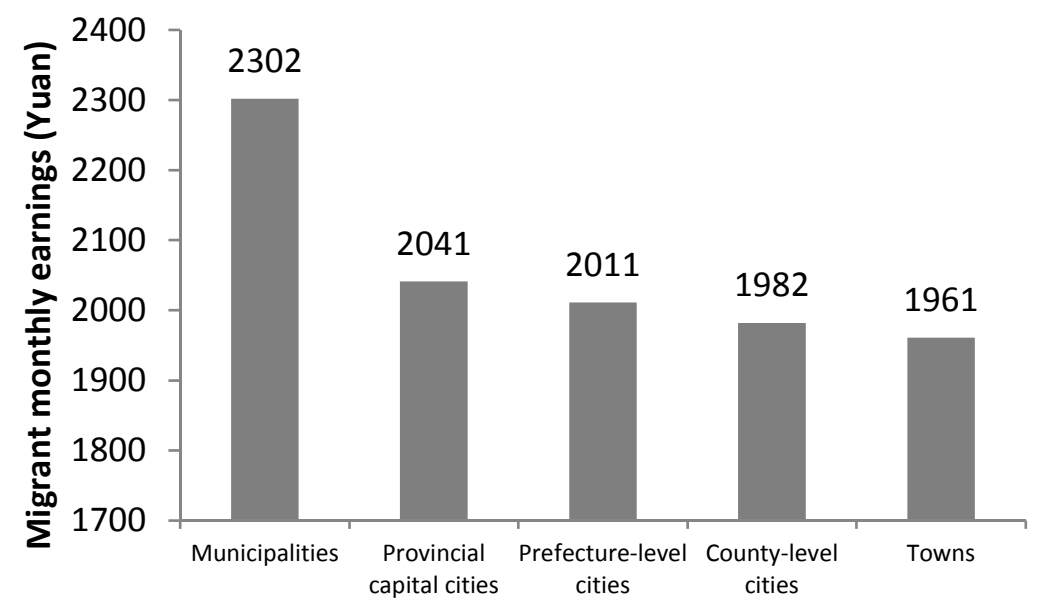

Figure 1. Migrants' monthly earnings by a hierarchy of destination cities, 2011. Four municipalities (shi) are under direct central government control: Beijing, Shanghai, Tianjin and Chongqing. Source: National Bureau of Statistics of China (2011).

have been gradually eroded (Bosker et al. 2012). A growing number rural of migrants have moved to nearby or remote cities seeking economic opportunities, especially after the early 1990s (Zhao 2005). According to the migrant monitoring report by China's National Bureau of Statistics, as of 2011 the total number of migrants in China reached 252.8 million, 53 per cent of whom were within-province migrants and 47 per cent inter-province migrants. Geographically, the major migration direction has been from the central and western provinces to southern and eastern coastal regions. Almost half of the migrants have been in the Pearl River delta and the Yangtze River delta.

Rural migrant labour markets are different from local resident labour markets in many aspects. Nationwide, about 65 per cent of migrant workers are male. While the majority of rural migrants are young, the percentage of older migrants is on the rise. In 2011, the number of rural migrants aged 40 years or older already accounted for 38 per cent. In general, the level of education and training is relatively low. The national survey data indicate that only 60 per cent of rural migrant workers received a middle-school education, and close to 70 per cent of them never have any vocational training.

It has been argued that the contribution of rural migrant workers has particularly helped to boost rapid industrialization and urbanization processes in China over the last three decades. The cheap labour costs offered by rural migrant workers enhance China's global competitiveness in developing its export-oriented economy. Manufacturing sectors provide the most important channel by which 36 per cent of migrant workers find their employment. Nationwide, only 5 per cent of rural migrants are self-employed in various cities, even though self-employment is identified as the significant venue for upward social mobility, through which rural migrants can be effectively assimilated into urban development. On average, rural migrant workers earned 2,049 yuan monthly (equivalent to US\$328) in 2011. There is a noticeable geographical variation in the earnings of migrant workers, especially across various levels of migration destination cities (Figure 1).

\section{Earnings determinants in urban migrant labour markets}

There are many factors that determine the income of individual migrant workers in urban labour markets. These factors may be related to individual abilities that characterize the supply side of labour markets (Kim and Park 2004; Chiquiar and Hanson 2005; Lu and Song 2006; Gries et al. 2011). They 
Yu et al.: Geographic structure of the migrant labour market in China

may be associated with industrial or firm characteristics that shape the demand side of labour markets (Lu and Song 2006; Li and Huang 2010). Beyond micro-scale mechanisms embedded in migrant labour markets, macro-scale factors may also play a role in determining the labour market performance of individual labourers (Zhao 2005; Zhan 2011). Inter-regional inequality in economic growth and change, structural variation of sectoral development across regions, cultural differences embedded in various local labour markets, institutional barriers in segmenting labour markets, and constraining labour mobility are some of the macro-scale factors that shape the dynamics of migrant labour markets in China (Fan 2002; Xu et al. 2006; Wang and Wu 2010). Also, it is argued that migrant labour markets are greatly separated from local resident labour markets in Chinese cities (Zhao 1999; Fan 2002; Xie 2007).

Methodological individualists focus on the role of individuals and firms in shaping labour market outcomes. Neoclassical microeconomic theories explain labour market outcomes by reasoning the dynamic relation between labour supply and demand. Under the assumption of rational behaviour by job seekers and employers, the wages and other economic compensations of individual labourers are determined by the personal abilities of individuals and job characteristics defined by a firm. Many studies are conducted to identify empirically the extent to which individual earnings are determined by workers' personal abilities and constraints. One of the pioneering works in investigating the return to human capital is Mincer's earnings equation, in which education level and training are considered explicitly as determining one's earnings (Mincer 1958, 1970). Many researchers have followed this line of reasoning and applied his theory in studying earnings determinants in various labour markets, including migrant labour market outcomes in China. It is widely argued that the returns from school education and vocational training vary across different labour markets (Fan 2001; Pekkala 2003; Guo and Zhang 2011; Fu and Gabriel 2012). In studying migrant labour markets, there are debates on the market return to education and training. Some researchers claim that the reward from school education for rural-urban migrants is not substantial, especially as it is compared to non-migrated workers (Yue et al. 2009; Fu and Ren 2010). Some argue further that vocational training has significant impacts on migrant earnings (Huang 2000; Cai 2007). In addition to education and training, work experience or seniority is often viewed as a significant determinant of individual earnings. Age is a common measure of seniority in the classic earnings equation. The effect of experience is normally detected in a parabolic pathway, using two variables of age and age-squared, with an inverted-U relationship included in the related model. In many case studies of migrant labour markets in China, age is identified as a significant positive determinant of migrant earnings (Wang and Wu 2010; Giulietti et al. 2012). However, in a study the 'new generation' of migrants in China, Yang and Jiang (2008) found that in comparing new-generation migrants and firstgeneration migrants with a similar migration duration, the income of the younger group was actually higher (Yang and Jiang 2008). This finding implies that there is a generational difference in earnings that may complicate the age effects on earnings in migrant labour markets. Language skill is often considered a significant constraint in migrant labour markets. Many researchers believe that better linguistic competence is of great importance for immigrants to achieve higher occupational prestige and higher income in destination cities (Kossoudji 1988; Akresh 2008; Akresh and Frank 2011). In the context of China, some case studies also show that the proficiency of Mandarin is a very important determinant for migrant labour market performance (Gao and Smyth 2011).

Recent studies on social capital and its relation to labour market outcomes contribute greatly to understanding the dynamics of migrant labour markets. Social capital may be defined as the fruit of social networks, consisting of the expectative benefits derived from the preferential treatment and cooperation that exist between individuals and groups (Coleman 1988). Job-seeking channels is one of the major topics in studying the role of social networks in migrant labour markets. It is recognized that 
many people find jobs not only though formal channels such as employment agencies or direct applications, but rather use their social networks (Granovetter 1973; Granovetter 1974; Marsden and Campbell 1990; Yang and Che 2003). In studying Chinese labour markets, researchers argue that social networks in migrant destination cities are not only a job-seeking channel but rather a fundamental prerequisite that opens the gate for rural-urban migrants to access urban labour markets (Li 2001; Chen 2004; Zang and Pan 2011). Granovetter argued that jobs found through social networks could be better paid and more satisfying to employees, and that weak social ties have greater positive impacts than strong ties on improving labour market outcomes. The weak tie and strong tie are normally distinguished by age of the relationship, frequency of contact, emotional attachment, reciprocity, and kinship (Granovetter 1973, 1974). Specifically, as related to migrant study in China, the kinship network is normally regarded as a strong tie. Many studies have provided evidence to support Granovetter's argument on the effects of social networks on income differentiations in migrant labour markets (Borghans et al. 2006; Franzen and Hangartner 2006). Others indicate that there is hardly any evidence showing the existence of significant wage differences between jobs found through social networks and through formal channels (Lin 1999; Mouw 2003). In terms of the effects of weak and strong social ties on migrant earnings, findings from different case studies also appear to be highly contradictory (Yang and Che 2003).

In addition to job-seeking channels, many studies have been conducted to understand the migrant income effects of other social network factors, including social participation (Palmer et al. 2011), friend and acquaintance networks in the cities (Boyd 1989; Ryan et al. 2008), residential neighborhoods (Aguilera and Massey 2003), and social trust (Cox 2000). Although the specific findings may vary, researchers generally believe that social capital and networks have a great impact on migrant earning performance. Compared to the linear effects of human capital, the social network effects are much more complicated. The strength and forms of the effects can also be different between the formal and informal sectors. In terms of Chinese migrant labour markets, some studies indicate that kinship networks and migrant social networks are of great importance to rural migrants. Comparatively, the effects of urban social network and social participation are relatively limited (Zhuang 2009; Liu et al. 2012). It is often argued that the effects of social capital are largely related to migration duration (Chou and Chow 2009), as well as to the economic development of the destination cities (Wang and Wu 2010). In sum, the role of social capital and networks as an important determinant of rural-urban migrant labour market performance in China is still widely debated in the literature. Little attention has been paid to explain geographical differentiation of the effects on migrant labour markets in China.

The above discussion highlights the role of micro- and meso-level factors in shaping individual incomes in labour markets. Macro-level factors such as institutional barriers and regional industry composition are also important determinants of individual earnings. In the context of China, some studies have identified the significant effects of regional employment regulation, the household registration system, and industry composition on the migrant labour market performance (Li 2004; Liu and Zhang 2007; Chen and You 2009).

The structuralist approach highlights the importance of wider institutional processes and focuses on the structure of the demand side of the labour market and its impacts on labourers' performance. The segmented labour market theory is the most commonly cited theory in this regard. It is argued that the labour market is segmented by institutional factors and social configuration. Institutional barriers are at the root, causing obstacles to labour mobility, and theoretically the existence of longterm equilibrium of the labour market is not warranted (Blonestone 1970; Bonacich 1972; Beck et al. 1978; Dickers and Lang 1985). In China, labour market segmentation in coastal regions is widely reported as a social phenomenon that is closely related to rural-urban migration. Migrant labour 
Yu et al.: Geographic structure of the migrant labour market in China

markets in coastal cities China are regarded as highly segmented due to institutional reasons, and migrant workers are often trapped in the lower end of the labour markets, with high turnover rates, low-level labour compensation and social security coverage, and relatively low return on human capital (Zhao 1999; Meng and Zhang 2001; Guo 2004; Howell 2011). Two elements have been frequently discussed in relation to migrant labour market segmentation in China. First, the role of gender-that is, migrant labour has been widely recognized as being gender-segmented in transitional China (Fan 2003a; Fan 2003b; Xu et al. 2006). The preference for male migrant workers, as well as the subordinate positions of female migrants, has been well documented (Meng 1998; Yang and Guo 1999; Lu and Song 2006). Second, the institutional barrier, as the household registration system (aka bukou) in the context of China, has also been argued as a major cause of labour market segmentation (Chan et al. 1999; Chan and Zhang 1999; Guo and Iredale 2004). However, more recently, there are rising debates on the role and significance of the bukou system on internal labour migration in China. Some scholars argue that among all disadvantages, the constraints of the bukou system is the fatal obstacle that prevents migrants from entering the urban mainstream and further settling in destination cities (Guo and Iredale 2004; Zhang 2012; Zhang and Tao 2012). Others claimed that the impact of the bukou system on migrants' livelihood in cities has declined substantially (Zhan 2011).

Regional industrial composition characteristics may also shape the structural characteristics of labour markets. In a study on migrant earnings_-based on migrant survey data collected in 2000 and 2008 in two cities in Shandong province- $-\mathrm{Li}$ and Huang claimed that the transformation from manufacturing to a service-dominated employment structure is one of the major reasons responsible for improvement of the migrant labour market performance and the change of migrant earning determinants $(\mathrm{Li}$ and Huang 2010). However, some researchers also claim that they can hardly find any evidence showing significant effects of industry type on migrant earnings (Gao 2006; Liu and Zhang 2008). The effect of self-employment on migrant labour market performance has also been highlighted in this regard. It is widely reported that self-employment is positively related to migrant labour market performance, and the proportion of self-employed migrants has increased rapidly in the last decade (Giulietti et al. 2012).

\section{Analytical framework and research hypotheses}

Research characterizing migrant labour markets are often empirically grounded. The above review of literature on the migrant labour markets in China indicates that rural-urban migrants are still largely clustered in the low-end labour market segments in urban China. An income gap between migrant workers and local labourers in urban China is evident. While it is reported that there is spatial variation in the earnings of migrant workers in China at different geographical scales (Gao 2006; Liu et al. 2007; Xie 2007), studies on the geographic structure of migrant labour markets are not substantial. This study attempts to characterize migrant labour markets across four city-regions and to investigate how earnings structures vary in different local migrant labour markets. In so doing, two central working hypotheses are developed, based on the conclusions drawn from the above literature review.

The first hypothesis: the characteristics of local migrant labour markets vary according to regional economic development conditions at the city-region level. More specifically, labour compensation is better in localities where regional economic activities are more concentrated, specialized, and productive, and where conditions and frameworks for market transactions are better established. Regional differences in economic wealth and productivity are commonly measured by differences in GDP and GDP per capita. Geographic concentration and sectorial specialization of economic activities are long recognized as important causes of varying economic growth and productivity across regions due to agglomeration economies (Drennan et al. 1996; Shaver and Flyer 2000; Kraetke 2007). Economic pro- 
ductivity determines income level and labour compensation in any given region. Regional differences in economic wealth and productivity are closely tied to spatial unevenness in labour market outcomes across regions (Stambol et al. 1998; Fan and Scott 2003; Martinkus et al. 2009). While migrant workers are often segmented at the lower end of local labour markets, regional differentials in labour compensations between migrant labour markets are still very much shaped by regional differences in economic productivity (Fan 2002). Institutional arrangements for market trade and transactions shape critically firm competitiveness and protection of workers' welfare level. Varying implementation of labour acts and regulations across localities may produce different sets of labour market compensations across regions (Blos et al. 1997). It is quite common in China that in economically sound regions, market transactions tend to be more regulated and workers are better protected (Xie and Hannum 1996; Gao 2006).

The second hypothesis: earnings determinants vary for local migrant labour according to the level of regional economic development at the city-region level. More specifically, in more developed regional economies, the return on human capital is higher, the effect of primary social networks is lower, and the effect of institutional and cultural barriers is weaker. Heterogeneity in the return on human capital is often thought to be related to the varying level of development attained by each regional economy (Fleisher et al. 2010; Batabyal and Nijkamp 2013). The sectoral mix and specialization of the regional economy represent important factors for such heterogeneity. This is because certain industrial sectors are more productive than others and firms in regions where specialization and agglomeration occur generate higher returns on human capital investment (Shaver and Flyer 2000; Storper and Scott 2009; Fleisher et al. 2010).

The effect of institutional factors on migrant earnings may vary spatially in China, where the implementation of reforms and open-door policies varies geographically, and openness of labour markets and the removal of institutional and cultural barriers differ from region to region (Lu and Wang 2013). Consequently, in more developed regions, it is expected theoretically that the effect of institutional and cultural factors on migrant earnings is weaker (Yan 1990; Shen 2013). Not much has been done on geographic variations in terms of the effects of social capital and networks. Nonetheless, theoretically, one can expect that in less developed economies family and kinship-based social networks play a more important role in people's wellbeing. This is because there are more informal and independent employment opportunities in a less developed region (Huang 2011), and there is normally a lack of opportunity to access formal and advanced social network channels (Yue et al. 2013). Consequently, migrants who enjoy better primary, family, and kinship-based social networks in less developed regions may find it easier to obtain employment opportunities in migrant labour markets. However, employment through such primary social networks normally provides less job compensation. In contrast, in more open and mature markets, advanced social networks may bring more economic opportunities that are often beyond the reach of one's primary social proximity. Migrants who develop better advanced social networks may have earnings advantages.

\section{Study area, data source, and analytical method}

Since the onset of reforms in 1978, coastal cities in China have been the major destination of intraand inter-provincial labour migrants. This study selects four city-regions in Fujian Province as the study areas (Figure 2). Historically, Fujian Province was well-known as a settlement frontier, receiving waves of migrants from northern China. Today, urban Fujian remains a major destination for rural migrants. According to the 2000 census, there were about 4.7 million migrants, about 2.2 million of whom arrived from outside Fujian Province, making Fujian the sixth most important destination for inter-provincial 


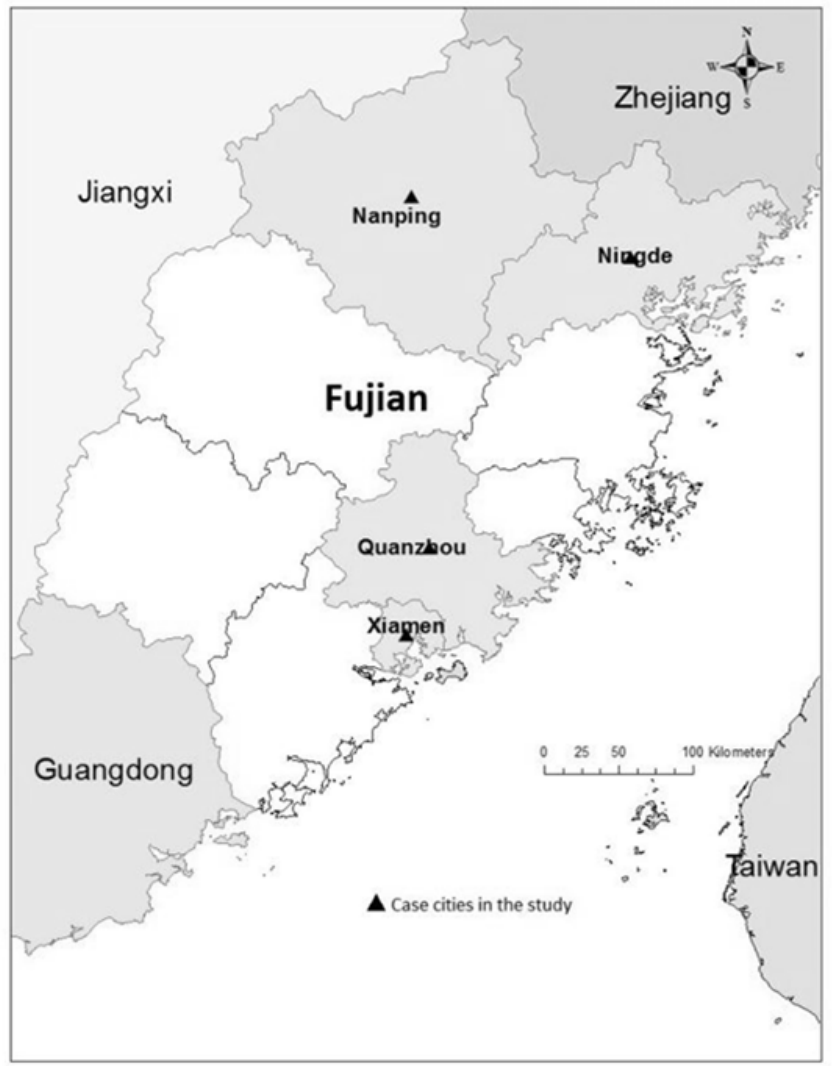

Figure 2. Map of the study area: Fujian province and four case cities.

migration in China. Another reason to select Fujian was its representativeness in migrant labour market studies. As a coastal province, Fujian has been at the forefront of adopting economic reforms and open-door policies. As part of the eastern China economic belt, Fujian connects the two most important economic centers of the Pearl River delta in the south and the Yangtze River delta in the north. Its economy is also heavily influenced by overseas investment, especially from Taiwan. The impressive pace of economic growth over the last three decades has created substantial employment opportunities in urban Fujian that cannot be filled by local labourers. Numerous rural migrants are employed in manufacturing and service sectors from its urban centers to its urbanizing countryside.

Table 1. General labor employment characteristics in Fujian, 2009.

\begin{tabular}{lr}
\hline Demographic characteristics & Index \\
\hline Total employment (millions) & 21.7 \\
Male and female employment ratio & 1.02 \\
Illiterate or semi-illiterate laborers (\%) & 7.7 \\
Laborers with primary school education (\%) & 31.5 \\
Laborers with middle school education (\%) & 31.5 \\
Laborers with high school or vocational school education (\%) & 13.1 \\
Laborers with junior college or above education (\%) & 9.1 \\
\hline
\end{tabular}

Source: Fujian Statistical Yearbook 2010.

Table 1 provides information about the demographic characteristics of labour employment in Fujian. Out of the total of 21.7 million labourers, male employees are slightly more numerous than females. The overall level of education attainment of the entire labour force is still relatively 
low, with almost 78 per cent of labourers having a middle-school or lower education. The average monthly employment income in an urban enterprise was is 2,400 yuan in 2009 . Almost half of the employment is in the manufacturing industry, 22.8 per cent in the service industry, and close to 10 per cent in the construction sector. The role of the state in providing employment has steadily declined. Less than 20 per cent of employment was provided by the state or collectively owned firms or institutions. Privately owned firms and self-employment accounted for more than 40 per cent of total employment, and foreign-owned firms provided almost 23 per cent of employment in urban Fujian.

Table 2. Regional economic disparities of four case cities, 2009.

\begin{tabular}{lrrrr}
\hline & Xiamen & Quanzhou & Ningde & Nanping \\
\cline { 2 - 5 } Total population (millions) & 2.52 & 7.86 & 3.04 & 2.90 \\
Urban population (million) & 2.06 & 4.11 & 1.23 & 1.40 \\
GDP (100 million Yuan) & 1737.23 & 3069.5 & 612.28 & 621.65 \\
Primary industry (\%) & 1 & 4 & 19 & 22 \\
Secondary industry (\%) & 47 & 58 & 40 & 40 \\
Tertiary industry (\%) & 52 & 38 & 41 & 38 \\
GDP per capita (yuan/person) & 68,938 & 39,227 & 20,174 & 21,473 \\
\hline
\end{tabular}

Source: Fujian Statistical Yearbook 2010.

The selected city-regions represent different types of economic development patterns in Fujian. While Xiamen, Quanzhou, and Ningde are all located in the coastal area (Figure 2), their economic characteristics vary greatly. Xiamen is a state-designated Special Economic Zone, enjoying preferential economic policies to attract investment since 1980. As is shown in Table 2, with 2.5 million people, Xiamen is the city with the smallest population size but the highest proportion of urban population among the four city-regions. GDP per capita in Xiamen is significantly higher than in the other three city-regions. In terms of industrial composition, primary industry in Xiamen is negligible and its economy is essentially pillared by secondary and tertiary sectors. Quanzhou is the famous hometown of a large number of overseas Chinese. It is also a national-level manufacturing center, and secondary sector output accounts for 58 per cent of its GDP. There are over seven million people in Quanzhou, and its GDP is almost twice as large as it is in Xiamen. Both Xiamen and Quanzhou represent relatively better off regions in the province. Ningde is located at the mountainous and hilly coastal area; it represents a less developed region in coastal Fujian. Both its GDP and GDP per capita ranked the last place among four city-regions. Nanping is an interior city-region with a mountainous landscape; it has been traditionally the poorest region in the province. Primary production still accounted for 22 per cent of its GDP, and the secondary sector for 40 per cent of GDP. In sum, based on the GDP and GDP per capita, Xiamen and Quanzhou will be regarded as developed regions in this study, whereas Ningde and Nanping will be categorized as less developed regions.

The dataset in this study was collected through a questionnaire survey jointly conducted by Center for Population and Development Research at Fujian Normal University and the Fujian Provincial Population and Family Planning Commission in December 2009. The provincial migrant population database, based on the fifth national census and established by the Fujian Provincial Population and Family Planning Commission, was used as the sampling frame. Potential respondents were those migrants in the database who were 15 to 64 years old, employed as labourers or doing business, migrated out of the boundaries of their original county-level administrative units, and had lived in the current places of destination for more than one month. The survey was based on a four-step proportional probability sampling procedure to randomly select the county-level, 
Yu et al.: Geographic structure of the migrant labour market in China

township-level, and community (village) level administrative units, and then randomly select 10 women migrants and 5 male migrants in each of the selected sample units. As a result of the above procedure, 17 county-level administrative units, 59 sub-district (township) level administrative units, and 185 community (village) level administrative units were covered in the survey, and a total of 3,011 respondents were interviewed, including 1,994 responses from women migrants and 1,017 responses from men migrants. As the proportions of women and male migrants in the total migrant population were close to 50 per cent in the sample frame, we randomly selected half of the responses $(1,016)$ from those of women respondents and combined them with those of male respondents to form a new dataset for the analysis. We identified and deleted 22 invalid responses in the process of data entry, and obtained a dataset of 2,011 valid responses, including 997 responses from women migrants and 1,014 responses from male migrants. Then, we selected the data of four city-regions out of the original dataset to conduct this research. A total of 1,473 migrants from the four city-regions are included in this study.

The questionnaire used to survey migrants was jointly designed by the Center for Population and Development Research at Fujian Normal University and the University of Lethbridge. The original questionnaire was adjusted and modified after a pre-survey with 100 migrants in Fuzhou City. The final questionnaire contains questions organized into six sections: basic personal information; migration process and experience; current employment status; current living conditions; social security status; and social participation and integration. Each part includes 15-25 questions, the majority of which are multiple choice, with a few sorting questions and fill-in-the-blank. A survey with one migrant normally lasted 40 to 120 minutes, depending on the ability of respondents to understand the questions. A total of 370 interviewers, all experienced social workers, two for each village-level unit, were fully trained by the questionnaire designers. After the survey, all of the 3,011 questionnaires were carefully examined one-by-one, using individual telephone confirmation to ensure the accuracy and completeness of each result, by members of the Center for Population and Development Research at Fujian Normal University.

In this study, the data analysis includes two parts. First, a descriptive analysis is conducted to understand the major characteristics and differences of the migrant labour market in the four city-regions. The descriptive analysis focuses on four major themes, including migrant demographic characteristics, market compensation, residential conditions, and industrial and occupational characteristics. Comparative descriptions of migrant labour markets provide a basis to contextualize the findings of the quantitative modeling of migrant earnings conducted in this study.

OLS regression models were developed for each of the four city-regions based on the survey data. The dependent variable in the regression models is the natural logarithmic form of monthly migrant earnings. With natural logarithmic transformation, the dependent variables become normally distributed (see Figure 3), and the model results of each explanatory variable can be interpreted as the percentage contribution rate of these factors on migrant earnings. However, monthly earnings can only partially reflect migrant labour market outcomes. Several important indicators of their labour market performance, such as housing status and insurance coverage, are not measured by the model. Given the fact that the housing and insurance expenses are possibly covered (or partly covered) by employers, and are counted as an important part of migrants' overall welfare in the cities, the earnings represent only a major part of the job compensation for migrant workers. Also, the values of their monthly earnings in the survey are based on migrants' subjective responses. It is possible that some over- or underreporting may exist. These limitations should be considered when assessing the model discussions. 

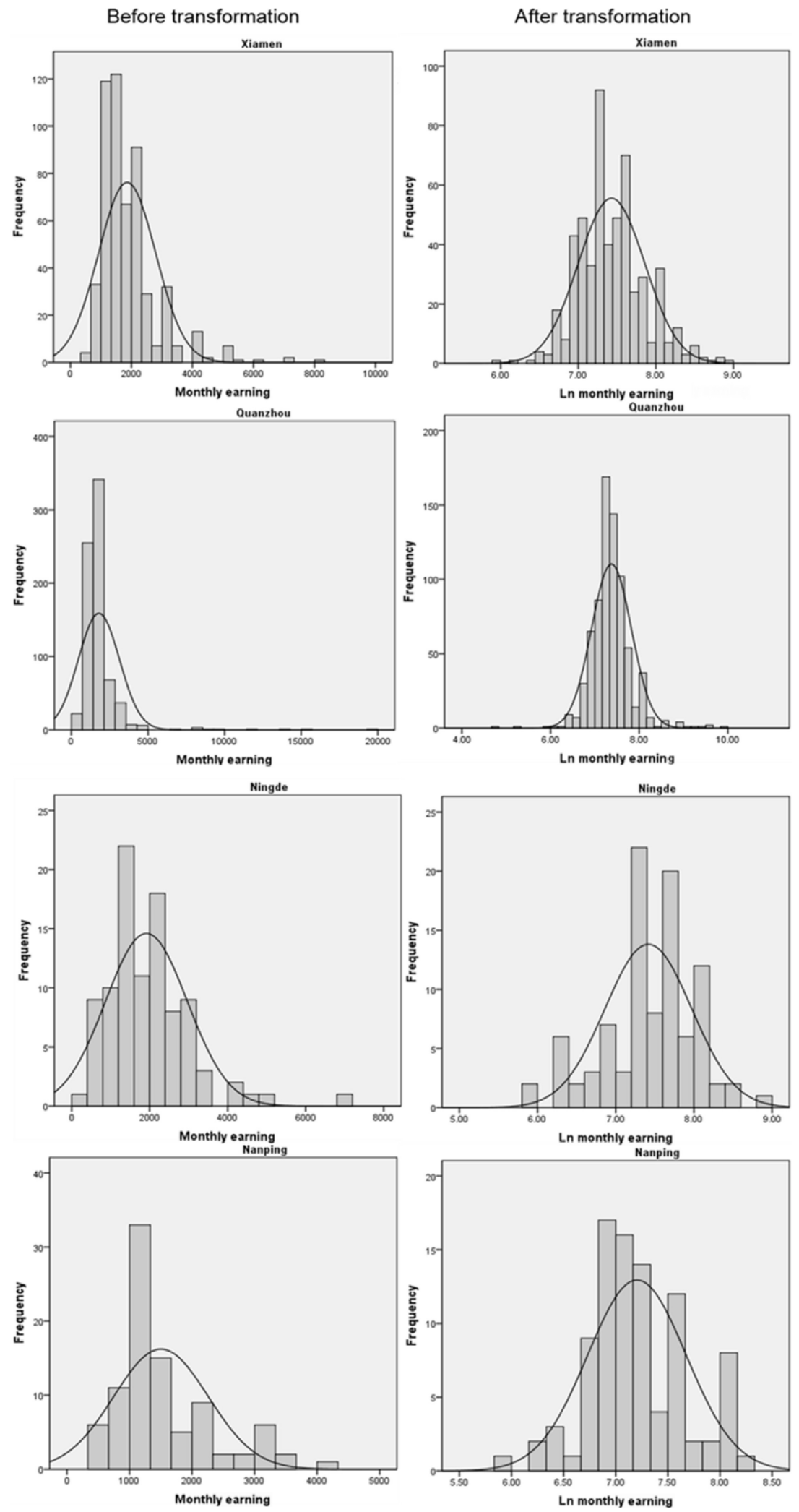

Figure 3. Distributions of monthly earnings before and after the natural logarithmic transformation in the four city-regions. 
Yu et al.: Geographic structure of the migrant labour market in China

Table 3. A list of regression model variables.

Total sample

Logarithmic form of average monthly earnings of migrants

Human and political capital

Age (average)

Age-squared (average)

Years of schooling (average)

Have been trained during migration (proportion)

Non-agricultural hukou (proportion)

Job types

Managers or professionals (proportion)

Vendors or Part-time workers (proportion)

Self-employed (proportion)

Social capital and network

Male (proportion)

Social circle - families and villagers (proportion)

Local residence duration (average)

Found current job through social networks (proportion)

Found current job through primary social networks (proportion)

Migration origin - intra-provincial (proportion)

Corporate characteristics

Manufacturing (proportion)

Construction (proportion)

Services sector (proportion)

\begin{tabular}{rrrr} 
Xiamen & Quanzhou & Ningde & Nanping \\
\hline 538 & 746 & 96 & 93 \\
7.43 & 7.37 & 7.42 & 7.2 \\
& & & \\
31 & 30 & 37 & 33 \\
961 & 900 & 1369 & 1089 \\
8.78 & 7.44 & 6.09 & 7.31 \\
0.35 & 0.34 & 0.22 & 0.34 \\
0.13 & 0.53 & 0.05 & 0.05 \\
& & & \\
0.18 & 0.11 & 0.07 & 0.06 \\
0.06 & 0.02 & 0.09 & 0.15 \\
0.15 & 0.09 & 0.30 & 0.22 \\
& & & \\
0.52 & 0.49 & 0.45 & 0.48 \\
0.45 & 0.35 & 0.47 & 0.49 \\
6.33 & 5.21 & 5.24 & 5.75 \\
0.20 & 0.28 & 0.42 & 0.20 \\
0.33 & 0.55 & 0.54 & 0.35 \\
0.42 & 0.19 & 0.30 & 0.46 \\
& & & \\
0.49 & 0.81 & 0.43 & 0.30 \\
0.05 & 0.02 & 0.10 & 0.20 \\
0.21 & 0.11 & 0.25 & 0.29 \\
\hline & & &
\end{tabular}

The explanatory variables are selected based on the analytical framework discussed in the previous section. In total, 15 independent variables were eventually included in the model, and categorized into three groups: human and political capital, social capital and network, and firm characteristics (Table 3).

\section{Characteristics of migrant labour markets in the case city-regions}

\section{Demographic characteristics of rural migrant workers}

Table 4 shows average age and age distribution of the surveyed migrants in the case regions. The average age of the respondents ranges from 30 years old in Quanzhou to 37 years old in Ningde. In general, rural migrant workers tend to be younger in the economically more developed areas than in the less developed areas.

Table 4. Average age and age distribution of surveyed migrants in four case cities, 2009.

\begin{tabular}{lrrrr}
\hline & Xiamen & Quanzhou & Ningde & Nanping \\
\cline { 2 - 5 } Average age (years) & 31 & 30 & 37 & 33 \\
Age distribution (\%) & & & & \\
$\quad$ Younger than 20 years old & 8.9 & 11.4 & 1.5 & 2.6 \\
20-29 years & 47.4 & 49.2 & 30.9 & 42.1 \\
30-39 years & 41.5 & 36.7 & 57.4 & 53.9 \\
$\quad$ 40 years and older & 2.2 & 2.7 & 10.3 & 1.3 \\
\hline
\end{tabular}


Table 5. Migrant educational attainments in four case cities, 2009.

\begin{tabular}{lrrrr}
\hline & Xiamen & Quanzhou & Ningde & Nanping \\
\cline { 2 - 5 } Average schooling years (years) & 9 & 7 & 6 & 7 \\
Education attainment (\%) & & & & \\
No education & 8.8 & 14.5 & 30.2 & 14.0 \\
Primary school & 14.1 & 24.3 & 21.9 & 32.3 \\
Junior high school & 45.2 & 50.8 & 36.5 & 39.8 \\
Senior and vocational school & 23.6 & 8.5 & 6.3 & 12.9 \\
College or above & 8.3 & 1.9 & 5.1 & 1.0 \\
\hline
\end{tabular}

Education attainment is argued to be one of the most fundamental earnings determinants in the literature. According to the survey, there is little difference in average number of schooling years among the four city-regions. The average year of schooling ranges from six years in Ningde to nine years in Xiamen (Table 5). Given the fact that nine years of formal schooling education is the national standard of compulsory education, the education attainment of the migrant workers is relatively low in all the case city-regions.

\section{Labour market compensation for migrants}

Table 6 presents the income distribution of migrants in the case city-regions. The average monthly income of migrants ranges from 1,503 yuan in Nanping to 1,918 yuan in Ningde. Most of migrants earn 1,000-2,000 yuan monthly. Monthly average earnings of the migrants in Xiamen are 1,858 yuan, which is the second-highest earnings among the case city-regions. It is noteworthy that the percentage of the extreme low income group (less than 1,000 yuan) in Xiamen is only 12.5 which is the lowest among the four case cities. Compared to the other three cities, the relatively low standard deviation of income indicates that the wage level of migrant workers in Xiamen is not as polarized. The average monthly income in Quanzhou is 1,796 yuan, ranking third among the case regions. Similar to Xiamen, the percentage of the extreme low income group (less than 1,000 yuan) in Quanzhou is relatively low. Seven out of ten migrants earn 1,000-2,000 yuan in this city region.

Table 6. Average monthly income and income distributions of migrants in four case cities, 2009.

\begin{tabular}{|c|c|c|c|c|}
\hline & Xiamen & Quanzhou & Ningde & Nanping \\
\hline Average monthly income $(\mathrm{CNY})^{*}$ & 1,858 & 1,796 & 1,917 & 1,503 \\
\hline \multicolumn{5}{|l|}{ Income distribution $(\%)$} \\
\hline Less than 1,000 yuan & 12.5 & 13.3 & 20.9 & 32.3 \\
\hline $1,000-2,000$ yuan & 67.1 & 70.6 & 53.2 & 51.6 \\
\hline More than 2,000 yuan & 20.5 & 16.0 & 26.0 & 16.2 \\
\hline
\end{tabular}

Ningde is often viewed as a less developed city in coastal Fujian. However, the results of the survey about the migrant labour market performance in Ningde have shown a different picture. The average monthly income of the respondents in Ningde is 1,918 yuan, the highest among the case regions. It is also important to point out that 75 per cent of migrant workers earn less than 1,500 yuan a month in Ningde. Moreover, the standard deviation of their income is relatively high, and the income of rural migrants in Ningde is more polarized than that in the other three city-regions. Nanping is the interior city in this study. The average monthly income in Nanping is the lowest for migrants among 
Yu et al.: Geographic structure of the migrant labour market in China

the case study areas. The major characteristic of income distribution in Nanping is that about 35 per cent of rural migrants earn less than 1,000 yuan and the number of low-income migrant workers is significantly higher than the other three city-regions.

Table 7. Social insurance coverage of migrant workers in four case cities (\%).

\begin{tabular}{lcrrc}
\hline Type of insurance & Xiamen & Quanzhou & Ningde & Nanping \\
\cline { 2 - 5 } Pension insurance & 34.6 & 3.2 & 3.1 & 7.5 \\
Medical Insurance & 46.5 & 5.5 & 2.1 & 3.2 \\
Unemployment insurance & 29.7 & 1.6 & 1 & 4.3 \\
Injury insurance & 39.4 & 14.9 & 9.4 & 4.3 \\
\hline
\end{tabular}

* According to the Law of Social Insurance of the People's Republic of China, established in 2010, there are currently five types of social insurance in China: pension insurance, medical insurance, unemployment insurance, injury insurance, and maternity insurance. However, the emphasis of this part of the thesis is on the general migrants, therefore, the strongly gender-related maternity insurance is not included in the discussion.

The coverage of the state social security program represents another indicator of employment compensation in labour markets. Some researches even indicate that the income gap between migrant workers and local labourers may be largely attributed to the difference in their social welfare (Xie 2007). As is shown in Table 7, the coverage for rural migrant workers is very low in Quanzhou, Ningde and Nanping. The coverage rates of all four available insurances are lower than 15 per cent; most of the rates are less than 5 per cent. The results indicate that a majority of the rural migrant workers in these three city-regions haven't received any social security as their working benefits, even if the coverage of these insurances is mandatory according to Chinese labour regulations. Comparatively, social insurance coverage is remarkably higher in Xiamen than the other three cityregions. The coverage rates of all four types of social insurance in Xiamen are between 30 and 50 per cent. This finding indicates a higher degree of compliance with labour regulations and policies in Xiamen.

\section{Migrant residential conditions}

Housing conditions of rural migrants in the four case city-regions can be categorized into three types (Table 8). Housing Type I is Quanzhou. The average housing area for migrants in Quanzhou is the lowest among the four cities. This low rate of living space is because 74 per cent of migrant workers in Quanzhou live in dormitories with shared rooms, provided by the employers. The proportion of dormitory living is much higher in Quanzhou than in the other three city-regions. This difference results from the fact that Quanzhou is a strong manufacturing center compared to the other three city-regions, and manufacturing plants normally provide dormitory housing. Housing Type II includes Xiamen and Nanping. The average housing area for migrant workers in these two cities is about 10 square metres per person, and about 75 per cent of migrants live in rented rooms in apartment buildings or houses. It is worthwhile to note that the proportion of migrant workers who have bought their own apartments in Housing Type I and Type II cities is lower than 2 per cent. Ningde belongs to Housing Type III in our survey. With 31 square metres per person as the average housing area, rural migrants in Ningde live in a much bigger housing space compared to the other three cities. This result is not unexpected, because 40 per cent of rural migrants in this city-region have bought their own residence in Ningde. The unique housing condition in Ningde might be closely related to the high income levels, older population structure, and high proportion of self-employment of migrants in this region. 
Table 8. Housing status of migrants in four case cities, 2009.

\begin{tabular}{lcrrr}
\hline & Xiamen & Quanzhou & Ningde & Nanping \\
\cline { 2 - 5 } Average housing area per respondent $\left(\mathrm{m}^{2}\right)$ & 10.2 & 7.12 & 30.53 & 9.66 \\
Housing type (\%) & & & & \\
$\quad$ Dormitory provided by employers & 17.1 & 73.6 & 12.5 & 21.5 \\
$\quad$ Rental housing & 76.1 & 22.3 & 44.8 & 72.0 \\
$\quad$ Commercial housing & 2.0 & 0.7 & 40.6 & 2.2 \\
$\quad$ Others & 4.8 & 3.4 & 2.1 & 4.3 \\
\hline
\end{tabular}

\section{Industrial and occupational characteristics of migrant workers}

The share of migrant employment by industry is generally similar in Xiamen, Ningde, and Nanping. Migrant workers in these city-regions were mostly employed in manufacturing and service. The proportion of migrants employed in these industries is between 30 and 40 per cent. Comparatively, the industrial structure in Quanzhou was much more concentrated in manufacturing activities, which employ 80 per cent of the migrant workers.

Private economy is well developed in Fujian, and becomes an important provider of employment in the province. The proportion of migrant workers employed by privately owned firms in all the case city-regions is relatively high, whereas the proportion of state-owned firms is extremely low. However, there are regional differences in employment by firm type. About 72 per cent of the respondents in Quanzhou are employed by privately owned firms. In Nanping and Ningde, the proportion by privately owned firms is about 40 per cent. In Xiamen, the employment share by privately owned firms is even lower, but 35 per cent of migrant workers are employed by foreign-owned or -funded firms. In the other three city-regions, the role of foreign-owned firms is not significant in providing employment opportunities to migrant workers. It is well recognized that the foreign-owned or -funded firms tend to comply more with employment policies and labour regulations as compared to privately owned firms in China. The above result may explain why migrant workers have high social insurance coverage in Xiamen.

For occupational structure, not surprisingly, most migrant workers work as unskilled general labourers. About 78 per cent of migrant workers in Quanzhou are in this category. This is expected, given the concentration of migrants in the labour-intensive manufacturing activities in Quanzhou. In the other three city-regions, unskilled general labourers accounted for about 50 per cent of migrant workers. With regard to other occupation types, close to 20 per cent of the respondents in Xiamen work as managers or professionals, with high occupational compensation. This proportion is much lower in the other three city-regions. Comparatively, for jobs with extremely low occupational compensation, such as venders or part-time workers, the highest proportion (14 per cent) is found in Nanping. The proportion of self-employed migrants (21 per cent) in this region is also relatively high. In Ningde, 30 per cent of the respondents claimed that they owned a business at the time of the survey. The proportion is the highest among the four cities. It is widely reported in the literature that the economic return from self-employment is significantly higher than other occupations. This result partly explains why migrant income levels and residential conditions of migrants are better in Ningde than in other city-regions, especially considering the relatively poor regional macroeconomic development. However, the social insurance coverage rate in Ningde is extremely low. This may be because the self-employed often find it unnecessary to enroll in these insurances. 
Yu et al.: Geographic structure of the migrant labour market in China

\section{Determinants of labour market outcomes}

Four regression equations were established to identify the earnings determinants in migrant labour markets in the four selected case regions. All the models are statistically significant. Table 9 presents how each independent variable behaves in the regression models, and how the earnings coefficients differ across the different case regions. The adjusted $\mathrm{R}^{2}$ value of the four models ranges from 0.165 to 0.321 . In addition, several regression diagnoses-including homoscedasticity test, multicollinearity test, Durbin-Wu-Hausman test—have been repeatedly implemented to ensure the model met all the regression assumptions. With several adjustments, the heteroscedasticity, multicollinearity, and endogeneity issues have been largely addressed and controlled in the final models. Given all that, the regression analyses are reasonably successful. The model results are valid and reliable.

Human capital is associated with four basic elements: school education, vocational training, seniority and experience, and professional skills. Seven variables are included in this study to depict the effects of these elements: age, age-squared, years of schooling, training experience, and occupation type (including three dummy variables: managers or professionals, vendors or part-time workers, and self-employed). In general, migrant labour markets in developed regions of Xiamen and Quanzhou seem to be much more sensitive to human capital, especially in Quanzhou. In contrast, these variables are mostly insignificant in Ningde and Nanping. The effects of specific variables also vary across space. First, two fundamental variables that measure human capital, school education and training experience, are only significant in the Xiamen and Quanzhou models. The reward rate of each schooling year is around 2.5 per cent in both cities. In contrast, the coefficient of school education is smaller and insignificant in Nanping, and even negative in Ningde. "Have been trained during migration" shows a greater effect in Quanzhou. The contribution rate to migrants" earnings is 12.5 per cent, which is 3.5 per cent higher than that in Xiamen.

The seniority and experience of migrants are jointly measured by the variables "age" and "age squared." These two variables are only significant in Quanzhou. As expected, the effect of age is significantly positive, albeit at a decreasing rate. The reward rate of one year older is 4.9 per cent in monthly earnings in Quanzhou. This finding indicates that work experience is an important determinant, while the migrant labour market in Quanzhou is largely a youth-dominated market. It is worthwhile to notice that within the developed regions, the effects of specific variables also vary across space. In Xiamen, both formal education and skills training have a significant impact on migrant earnings, but the seniority measured by age and age-squared is not statistically significant. In Quanzhou, all four of these variables are significant.

The professional skill of labourers is measured by the occupation type. Three dummy variables are included: managers or professionals, vendors or part-time workers, and self-employed. The reference group is the "general and other labourers." Similar to other human capital-related variables, the professional skill shows greater effect in developed regions. Specifically, being a manager or professional can effectively improve one's earnings in Xiamen and Quanzhou by around 25 per cent, whereas this variable is insignificant in Ningde and Nanping. Next, to be self-employed is also found to be a very efficient way to improve migrants' labour market outcomes in developed regions. The variable "to be self-employed" is highly significant in Xiamen and Quanzhou, with proportions as high as 33.2 per cent.

The disadvantage of being a vendor or part-time worker is obvious in Xiamen and Nanping. The results further indicate that this disadvantage is even worse in the underdeveloped regions; that is, migrants in Ningde and Nanping who were engaged in these occupations earned around 
Table 9. Regression results of four models, 2009.

\begin{tabular}{|c|c|c|c|c|}
\hline & Xiamen & Quanzhou & Ningde & Nanping \\
\hline Constant & $6.613 * * *$ & $6.157 * * *$ & $7.298 * * *$ & $6.993 * * *$ \\
\hline Age & 0.018 & $0.049 * * *$ & 0.024 & 0.001 \\
\hline AGE SQUARED & $-2.35 \mathrm{E}-05$ & $-0.001 * * *$ & $-2.70 \mathrm{E}+05$ & $-1.22 \mathrm{E}-05$ \\
\hline Years of schooling & $0.027 * * *$ & $0.023 * * *$ & -0.009 & 0.018 \\
\hline Have been trained during migration & $0.098 * * *$ & $0.128 * * *$ & -0.009 & $1.97 \mathrm{E}-01$ \\
\hline \multicolumn{5}{|l|}{ Job types (reference: other labourers) } \\
\hline Managers or professionals & $0.282 * * *$ & $0.217 * * *$ & 0.385 & 0.089 \\
\hline Venders or Part-time workers & $-0.158 * *$ & 0.019 & -0.277 & $-0.306 * *$ \\
\hline Self-employed & $0.296 * * *$ & $0.332 * * *$ & 0.177 & 0.208 \\
\hline Non-agricultural hukou & 0.029 & 0.017 & 0.152 & 0.153 \\
\hline Male & $0.165 * * *$ & $0.138 * * *$ & $0.406^{* * *}$ & $0.274 * * *$ \\
\hline Families and villagers based social circle & -0.025 & 0.016 & $-0.256 * *$ & -0.080 \\
\hline Local residence duration (unit: year) & 0.006 & $0.011 * *$ & 0.012 & $0.033 * * *$ \\
\hline Found current job via primary social networks & -0.002 & $-0.008 * *$ & $-0.027^{*}$ & $-0.024 * *$ \\
\hline Intra-province migration origin & $1.20 \mathrm{E}-02$ & -0.062 & $-0.181^{*}$ & $-0.247 * *$ \\
\hline \multicolumn{5}{|l|}{ Industry type (reference: other industries) } \\
\hline Manufacturing & $4.00 \mathrm{E}-03$ & $0.127 * *$ & -0.149 & -0.113 \\
\hline Services sector & $-2.60 \mathrm{E}-02$ & -0.087 & -0.205 & -0.175 \\
\hline Adjusted $\mathrm{R}^{2}$ & 0.291 & 0.165 & 0.321 & 0.265 \\
\hline F-value & $15.719 * * *$ & $10.802 * * *$ & $3.998 * * *$ & $3.188 * * *$ \\
\hline
\end{tabular}

30 per cent less than general labourers, whereas, in Xiamen it is only 15.8 per cent, and is only insignificantly positive in Quanzhou. In conclusion, these results indicate that investments in human capital are significant in differentiating migrant earnings in developed regions but not likely in under-developed regions.

The effect of institutional barrier is directly measured by the bukou status. Unexpectedly, this dummy variable is insignificant in all four models. The result may imply a diminishing role of the bukou system on labour migration in China, which has been discussed in previous studies (Zhu 2007; Zhan 2011). However, it is worthwhile to note that the coefficients in the models for Ningde and Nanping (around 0.15) are much higher (around 0.02) than in the models for the developed regions. The effect of cultural tradition on the labour market is measured by a gender dummy variable. The finding indicates that the gender variable is highly significant in all four models. In fact, gender is the most stable and prominent variable among all the explanatory variables. However, the male values vary largely among regions. In Xiamen and Quanzhou, male migrants earn around 15 per cent more than females, but around 30 to 40 per cent more in Ningde and Nanping. These results confirm that the migrant labour market in China is largely gender-segmented regardless of the level of regional development. It further indicates that such segmentation is likely to be far more prominent in underdeveloped regions.

To measure the influence of social capital and networks, four major factors are included in the models: social circle status, local residence duration, job-seeking channels, and intra-province migration. In general, migrant labour markets in less developed regions like Ningde and Nanping are more sensitive to social capital and networks. To measure social circle status, one dummy variable, 
Yu et al.: Geographic structure of the migrant labour market in China

"family and village-based social circle," is included. The variable is significant in Nanping, with a sizable negative coefficient as -0.256 . The negative effect of primary social network and limited social interaction in under-developed regions provides evidence to support the second hypothesis of this study. Local residence duration is included as a surrogate measure in the models, to measure the effects of advanced social networks. The coefficient of this variable is positive and hence in line with our expectation. However, this effect on earnings is significant only in Quanzhou and Nanping and no anticipated geographic effects are detected.

The job-seeking channel is argued to be the most direct and explicit earning determinant in the category of social capital (Yue et al. 2009). In this study, the effect of job-seeking channels is measured by a dummy variable, "found current job via primary social networks." The variable is negatively significant in Quanzhou, Ningde, and Nanping. More importantly, the absolute values of coefficients in the models of Ningde and Nanping are higher than that in the Quanzhou model.

The fourth measuring of social capital and network is the dummy variable of intra-province migration origin. Whether a migrant is from within the destination province or beyond would largely effect the formation and adoption of one's social network in cities, especially primary social networks. It is expected that labour market outcomes of migrant workers in the under-developed regions are more shaped if one is from within the province. The result is in line with our expectation. The variable is statistically significant in both Ningde and Nanping but insignificant in Quanzhou and Xiamen. The negative effect of this variable indicates that primary social networks provide better employment opportunity by limited income reward.

The effect of industrial structure on the migrant labour market is quite weak. Almost all included variables are insignificant. One exception is the measure "to be employed in manufacturing," which shows significant effects in Quanzhou.

\section{Discussion and conclusions}

The sheer volume of rural-urban population migration in China in recent decades is unprecedented in human history. Millions of rural migrants move within or across provinces to the cities to find employment opportunities. There are growing concerns over the livelihood and survival of rural migrants in urban labour markets. This study focuses on labour market outcomes of migrant workers in urban Fujian. The study is based on a recent survey conducted in 2009. The findings indicate that the earnings of migrant workers are fairly low. The average monthly income of the surveyed migrant workers was 1,800 yuan, much lower than the provincial average of 2,400 yuan for all the employed in urban enterprises in Fujian, according to the 2009 Statistical Yearbook of Fujian. More than half of the surveyed migrant workers even earned less than 1,500 yuan a month. The social security coverage was also very low. Most migrant workers did not receive any coverage of social security programs as part of their employment benefits. The housing conditions for migrant workers in Fujian were quite poor as well. Most migrant workers lived in the crowded factory dormitories or small rental rooms. More than half of the surveyed migrant workers were employed in the manufacturing industry and privately owned firms. The findings confirm that rural migrants are very much confined at the lower end of urban labour markets in Fujian. They work mostly as unskilled general labourers, with little possibility for upward social mobility. Dormitory living and networking among themselves make it difficult for rural migrant workers to move out of the entrapment of migrant labour markers. 
The relationship between regional economy and migrant labour markets has been well documented in the literature (Greenwood 1981; Plane and Mulligan 1997; Rogers and Sweeney 1998). In Chinese migrant studies, this relationship has also been discussed. Many studies indicate that interprovincial migration in China has a strong connection to the spatial disparity in regional economic development between eastern and western China (Ma 1996; He and Pooler 2002; Fan 2005). The differentiation of regional economic development within eastern China also contributes to the movement pattern of rural migrants within and outside provinces (Mody and Wang 1997; Ouyang and $\mathrm{Fu}$ 2012). This study aims to understand the geographical differentiation of migrant labour markets across prefectural city-regions in Fujian by testing two hypotheses.

The first hypothesis - the characteristics of local migrant labour markets vary according to regional economic development conditions at the city-region level-has been well verified and confirmed in this study. Much research has confirmed the positive relations between migrant earnings and regional economic development at the inter-province level in China (Ma 1996; Ma 1999; Fan 2005). But very little attention has been paid to inter-city relations. This study sheds some light on the latter topic. It is found that migrant monthly earnings are varied across the four cities. More importantly, it is found that average income level is in general positively related to the level of regional economic development, but the relationship is not simply linear. The average migrant earnings in developed regions are relatively high, whereas in under-developed regions, they appear to be very high in one city and extremely low in another. Besides, the income differentiation in developed regions is seemingly not as polarized as it is in underdeveloped regions. The status of social insurance coverage also associates migrant labour markets with regional development conditions. In Xiamen, which is the only state council designated as a Special Economic Zone among the four case cities, the coverage rates of four types of social insurance are remarkably higher than in the other three regions, where the coverage rate is pitifully low. This "Xiamen exception" could be attributed to a better implementation of labour acts and regulations, and these benefit from Xiamen's first-mover advantage and its higher position in the urban political-economic hierarchy of China. Third, the residential condition of migrants shows strong connections to regional economic characteristics. Three types of residential structure have been identified: dormitory-based, rental-housing-based, and a large proportion of private-owned residences, and could be clearly connected to the regional industrial and employment composition.

Following the descriptive analysis, the quantitative analysis further confirms the second hypothesis that the determinants and influential factors of migrant earnings vary largely across regions. Specifically, the second hypothesis could be parsed into three aspects, focusing on varying effects of human capital, social capital and networks, and institutional and cultural barriers, respectively.

Migrant labour markets in China have long been reckoned as being gender-segmented (Fan 2003a; Fan 2003b; Xu et al. 2006), and the present research reinforces this argument. In particular, among the 15 explanatory variables, only "gender" is significant in all four models. All other variables behave differently in different regions. This result indicates that gender-based segmentation is widespread in the migrant labour market of China, and that gendered labour market segmentation is more prevalent in less developed regions.

It is hypothesized that in migrant labour markets with a more developed regional economy, the return on human capital is higher. The empirical result has clearly validated such hypothesis. The higher return on human capital in the general labour market of more developed regions has been widely acknowledged and been explained as a product of regional specialization and agglomeration (Shaver and Flyer 2000; Storper and Scott 2009; Fleisher et al. 2010). But very few researchers extend such a discussion to the migrant labour market in China. Our study shows that school education, 
Yu et al.: Geographic structure of the migrant labour market in China

experience and seniority, and vocational training and skills are mostly significant in elevating migrant earnings in the two developed case cities, whereas related variables are nearly muted in under-developed regions. As a result, migrant workers may effectively elevate their economic performance by investing in their human capital in more developed regions. In practice, this could galvanize migrants in developed regions to enhance their competitiveness vigorously, since the return is largely foreseeable. However, such traditional and direct methods are ineffective in less developed regions.

It is also hypothesized that in a migrant labour market with a more developed regional economy, the effect of primary social networks, which bring lower-income opportunities, is smaller. This study clearly validates this hypothesis. This study identifies four variables to capture the effects of social networks. Specifically, the measure of primary social networks includes three dummy variables: "familyand village-based social circle," "found current job via primary social networks," and "intra-province migration origin." Previous research provided evidence showing that primary social networks are negatively associated with migrant earnings in urban China (Chang et al. 2011). But the geographic variations in terms of the effects of social networks are still largely unknown. The results of this study indicate that the roles of social capital and networks are significant in less developed economies, and that migrant workers dependent upon primary social networks are often disadvantaged in urban labour markets in China. The results show that all three variables are significant in the model for Ningde, and two out three are significant in Nanping. The coefficients of these dummy variables are highly negative. For example, it is found that migrants who mainly communicate with families and villagers in cities would earn 25.6 per cent less than others in Ningde. In comparison, these variables are mostly insignificant in Quanzhou and Xiamen. The only exception is the "found current job via primary social networks" in the Quanzhou model. However, the extremely small coefficient $(-0.008)$ seems to reinforce the diminished role of primary social networks in Quanzhou. Besides, it is worth noting that of these three variables, "intra-province migration origin" behaves somewhat differently from what the literature indicates. In previous studies, scholars argued that short-distance migrants, especially intra-provincial migrants, may have the advantages of being more familiar with the migration destination and being able to exploit some benefits of pre-established social networks in the cities to enhance their earning power (Yang and Che 2003). However, this variable is significantly negative in both Ningde and Nanping, with relatively high coefficients $(-0.181$ and -0.247 , respectively). Three reasons could be attributed to this result. First, intra-province migrants may not be as ambitious as inter-province migrants. Because they have their family nearby, they can easily retreat to their home town. Therefore, they may deem their current jobs in the city merely as a complement to their family. All of these "advantages" make them more easily satisfied with the relatively low labour market compensation and resigned to live with it. On the other hand, with fewer family ties in cities, inter-province migrants are "compelled" to make more money to support themselves and their families. They thus have to be more independent and progressive. Besides, considering that inter-province migrants were already far away from their home, they can simply, relatively speaking, migrate to a bigger city nearby if they failed to find an ideal job. More importantly, the primary social networks may be associated with more informal and independent employment opportunities, which often provide less income. Local residence duration has been identified in several studies as a measure of advanced (urban) social networks of migrants in destination cities (Shah and Menon 1999; Mitra 2010). In this study, this variable is included to test if the effect of advanced social networks will be stronger in more developed regions. The result indicates that this variable is significant in Quanzhou and Nanping, and with even a greater impact in Nanping. More studies are needed to properly measure the geographic effects of advanced social networks on migrant earnings in China. 
The second hypothesis also states that in a migrant labour market with a more developed regional economy, the effect of institutional and cultural barriers is weaker. The implication is that market forces will be more thoroughly deployed in developed regions; therefore, institutional power such as the bukou system will gradually become irrelevant to migrant earnings (Yan 1990; Shen 2013). The dummy variable "non-agricultural bukou" is included in the model to test this hypothesis. First of all, the variable is insignificant in all four models. This result implies a diminished role of the bukou system in general, which is in line with several previous studies (Zhu 2007; Zhan 2011). Furthermore, compared to Xiamen and Quanzhou, the coefficient values of this variable in Nanping and Ningde are much higher. The effect of cultural barriers is measured by gender. It is expected that gender effect on migrant earnings diminishes from more developed to less developed economic regions. However, the empirical result shows that gender is significant in all four models, while the value of the coefficient decreases, as expected. This result indicates that gendered segmentation is widespread in the migrant labour market of China, and that gendered labour market segmentation is more prevalent in less developed regions.

In sum, it can be argued that migrant labour markets and their earnings determinants are geographically structured. The microeconomic mechanisms that determine migrant workers' earnings are largely affected by the processes of regional economic change. Transformation to a market-oriented economy from a socialist economy, integration into a global capitalist system, level of economic development, and structural characteristics are all geographically differentiated and constructed. The geographic perspective, thus, provides an important lens through which the dynamics of migrant labour markets in China can be understood. It is worthwhile to note that there are only four case cities included in this study, and they are all within Fujian province. While the four case cities are distinctly different in their economic background, including level of economic development, and industry structure, more empirical evidence is needed in future studies on the identified relationships in this study, in order to further understand the geographical structure of migrant labour markets in China.

\section{Acknowledgement}

We are grateful for the financial support provided by the International Development Research Centre (Grant No: 105447-001) and the University of Lethbridge (CREDO Award). We are thankful for the financial support provided by the China Natural Science Foundation (Project Approval Number: 41329001). This research is also supported by the Program for Professor of Special Appointment (Eastern Scholar) at Shanghai Institutions of Higher Learning. We also appreciate greatly the constructive comments and suggestions from anonymous reviewers.

\section{References:}

Aguilera, M.B., and D.S. Massey. 2003. Social capital and the wages of Mexican migrants: New hypotheses and tests. Social Forces 82(2):671-701.

Akresh, I.R. 2008. Occupational trajectories of legal U.S. immigrants: Downgrading and recovery. Population and Development Review 34:435-456.

Akresh, I.R., and R. Frank. 2011. At the intersection of self and other: English language ability and immigrant labor market outcomes. Social Science Research 40:1362-1370. 
Yu et al.: Geographic structure of the migrant labour market in China

Bao, S.M., G.H. Chang, J.D. Sachs, and W.T. Woo. 2002. Geographic factors and China's regional development under market reforms, 1978-1998. China Economic Review 13(1):89-111.

Batabyal, A.A., and P. Nijkamp. 2013. A multi-region model of economic growth with human capital and negative externalities in innovation. Journal of Evolutionary Economics 23(4):909-924.

Beck, E.M., P.M. Horan, and C.M. Tolbert II. 1978. Stratification in a dual economy: A sectoral model of earnings determination. American Sociological Review 43:704-720.

Blonestone, B. 1970. Labor markets and the working poor. Poverty and Human Resources 6:15-35.

Blos, M., P.A. Fischer, and T. Straubhaar. 1997. The impact of migration policy on the labour market performance of migrants: A comparative case study. New Community 23(4):511-535.

Bonacich, E. 1972. A theory of ethnic antagonism: The split labor market. American Sociological Review 37(5):547-559.

Borghans, L., B.T. Weel, and B.A. Weinberg. 2006. People people: social capital and the labor-market outcomes of underrepresented groups. NBER Working Paper No. 1198511.

Borjas, G.J., and G. Stephen. 1992. Self-selection and internal migration in the United States. Journal of Urban Economics (September):159-185.

Bosker, M., S. Brakman, H. Garretsen, and M. Schramm. 2012. Relaxing Hukou: Increased labor mobility and China's economic geography. Journal of Urban Economics 72(2-3):252-266.

Boyd, M. 1989. Family and personal networks in international migration: Recent developments and new agendas. International Migration Review 23(3):638-670.

Cai, F. 2007. Changes in the labor market trends and the urgency of skill trainings for migrant workers (in Chinese). Sociological Studies 5:10-13.

Chan, K.W., T. Liu, and Y. Yang. 1999. Hukou and non-hukou migrations in China: Comparisons and contrasts. International Journal of Population Geography 5:425-448.

Chan, K.W., and L. Zhang. 1999. The hukou system and rural-urban migration in china: Processes and changes. The China Quarterly 160:818-855.

Chang, K.-C., M. Wen, and G. Wang. 2011. Social capital and work among rural-to-urban migrants in China. Asian Population Studies 7(3):276-293.

Chen, A.J. 2004. Hou can peasantries find jobs in urban areas? A case study in Zhejiang province. Economic Research Report 34(2):36-38.

Chen, Z., and J. You. 2009. Factor analysis on the income level of off-farm workers based on quantile regression (in Chinese). Statistical Research 6:30-34.

Chiquiar, D., and G.H. Hanson. 2005. International migration, self-selection, and the distribution of wages: Evidence from Mexico and the United States. Journal of Political Economy 113(2):239-281.

Chou, K.L., and N.W.S. Chow. 2009. The roles of human capital and social capital in the economic integration of new arrivals from mainland China to Hong Kong. Habitat International 33(4):340-346.

Coleman, J.S. 1988. Social capital in the creation of human capital. American Journal of Sociology 94:95120.

Cox, E. (ed.). 2000. Diversity and Community: Conflict and Trust? Macmillan: Basingstoke. 
Dickers, W.T., and K. Lang. 1985. A test of dual labor market theory. The American Economic Review 75:792-805.

Drennan, M.P., E. Tobier, and J. Lewis. 1996. The interruption of income convergence and income growth in large cities in the 1980s. Urban Studies 33(1):63-82.

Du, Y., A. Park, and S.G. Wang. 2005. Migration and rural poverty in China. Journal of Comparative Economics 33(4):688-709.

Fan, C.C. 2001. Migration and labor-market returns in urban China: Results from a recent survey in Guangzhou. Environment and Planning A 33(3):479-508.

- 2002. The elite, the natives, and the outsiders: Migration and labor market segmentation in urban China. Annals of the Association of American Geographers 92(1):103-124.

- 2003. Rural-urban migration and gender division of labor in transitional China. International Journal of Urban and Regional Research 27(1):24-47.

- 2005. Interprovincial migration, population redistribution, and regional development in China: 1990 and 2000 census comparisons. Professional Geographer 57(2):295-311.

Fan, C. C., and A. J. Scott. 2003. Industrial agglomeration and development: A survey of spatial economic issues in East Asia and a statistical analysis of Chinese regions. Economic Geography 79(3):295-319.

Fleisher, B., H.Z. Li, and M.Q. Zhao. 2010. Human capital, economic growth, and regional inequality in China. Journal of Development Economics 92(2):215-231.

Franzen, A., and D. Hangartner. 2006. Social networks and labour market outcomes: The non-monetary benefits of social capital. European Sociological Review 22:353-368.

Fu, Q., and Q. Ren. 2010. Educational inequality under China's rural-urban divide: The hukou system and return to education. Environment and Planning A 42(3):592-610.

Fu, Y.M., and S.A. Gabriel. 2012. Labor migration, human capital agglomeration and regional development in China. Regional Science and Urban Economics 42(3):473-484.

Gao, W. 2006. Migrant workers employment status and income impact factors: A case study in Beijing, Shijiazhuang, Shenyang, Wuxi and Dongguan (in Chinese). Chinese Rural Economy 1:20-23.

Gao, W.S., and R. Smyth. 2011. Economic returns to speaking 'standard Mandarin' among migrants in China's urban labour market. Economics of Education Review 30(2):342-352.

Giulietti, C., G. Ning, and K.F. Zimmermann. 2012. Self-employment of rural-to-urban migrants in China. International Journal of Manpower 33(1):96-117.

Granovetter, M. 1973. The strength of weak ties. American Journal of Sociology 78:1360-1380. 1974. Getting a Job: A Study of Contacts and Careers. Chicago and London: University of Chicago Press.

Greenwood, M.J. 1981. Migration and Economic Growth in the United States: National, Regional, and Metropolitan Perspectives. New York: Academic Press.

Gries, T., M. Kraft, and C. Pieck. 2011. Interregional migration, self-selection and the returns to education in Brazil. Annals of Regional Science 46(3):707-732. 
Yu et al.: Geographic structure of the migrant labour market in China

Guo, C. 2004. Verification of dual labor market segmentation theory in China (in Chinese). Tsinghua University Education Research 8.

Guo, F., and R. Iredale. 2004. The impact of Hukou status on migrants' employment: Findings from the 1997 be migrant census. International Migration Review 38(2):709-731.

Guo, F., and S. Zhang. 2011. The effect of education discrimination and household discrimination on the wage differences between urban workers and migrant workers (in Chinese). Issues in Agricultural Economy 6:31-34.

He, J.S., and J. Pooler. 2002. The regional concentration of China's interprovincial migration flows, 1982-90. Population and Environment 24(2):149-182.

Howell, A. 2011. Labor market segmentation in Urumqi, Xinjiang: Exposing labor market segments and testing the relationship between migration and segmentation. Growth and Change 42(2):200-226.

Huang, H.L. 2000. The return to human capital of rural-urban migrants: A comparison study. The Economic Observer 36(2):45-47.

Huang, P.C.C. 2011. The theoretical and practical implications of China's development experience: The role of informal economic practices. Modern China 37(1):3-43.

Kim, Y.-M., and K.S. Park. 2004. The effects of workers' region of birth on labor market outcomes in the Republic of Korea. Developing Economies 42(GEOBASE):461-478.

Knight, J., and L. Yueh. 2009. Segmentation or competition in China's urban labour market? Cambridge Journal of Economics 33(1):79-94.

Kossoudji, S.A. 1988. English language ability and the labor market opportunities of Hispanic and East Asian immigrant men. Journal of Labor Economics of Education Review 6:205-228.

Kraetke, S. 2007. Metropolisation of the European economic territory as a consequence of increasing specialisation of urban agglomerations in the knowledge economy. European Planning Studies 15(1):127.

Li, M. 2004. Empirical analysis of employment distribution and income of rural-urban migrants in the context of labor market segmentation: A case study in Wuhan. Population Research 6:26-28.

Li, P. 2001. Employment And Institutional Change: The Job Search Process of Two Special Social Groups. Zhejiang: Zhejiang People's Publishing House.

Li, Q., and C. Huang. 2010. Analysis of migrant workers compensation changes, based on empirical studies of the two cities in Shandong (in Chinese). Economic Survey and Research 33(4):66-68.

Liang, X. 2001. Market transformation social relation and profession acquisition. Journal of Guangdong College of Young Cadres 4.

Lin, N. 1999. Social networks and status attainment. Annual Review of Sociology 25:467-487.

Liu, C., K. Otsubo, Q.X. Wang, T. Ichinose, and S. Ishimura. 2007. Spatial and temporal changes of floating population in China between 1990 and 2000. Chinese Geographical Science 17(2):99-109.

Liu, L., and C. Zhang. 2007. Human capital, social capital, enterprises institution or social environment: Wage determination model of migrant workers in Peal River Delta (in Chinese). Sociological Studies 6:20-24. 
2008. Wages for migrant workers in the Pearl River Delta: Determining factors. Social Sciences in China 3:23-25.

Liu, Y., Z. Li, and W. Breitung. 2012. The social networks of new-generation migrants in China's urbanized villages: A case study of Guangzhou. Habitat International 36(1):192-200.

Lu, Y., and F. Wang. 2013. From general discrimination to segmented inequality: Migration and inequality in urban China. Social Science Research 42(6):1443-1456.

Lu, Z., and S. Song. 2006. Rural-urban migration and wage determination: The case of Tianjin, China. China Economic Review 17(3):337-345.

Ma, L.J.C. 1996. The spatial patterns of interprovincial rural-to-urban migration in Chinaa, 1982-1987. Chinese Environment and Development 7:73-102.

- 2002. Urban transformation in China, 1949-2000: A review and research agenda. Environment and Planning A 34(9):1545-1569.

Ma, Z. 1999. Temporary migration and regional development in China. Environment and Planning A 31(5):783-802.

Marsden, P., and K. Campbell (eds.). 1990. Recruitment and selection processes: the organization side of job searches. New York: Cambridge University Press.

Martinkus, B., S. Stoskus, and D. Berzinskiene. 2009. Changes of employment through the segmentation of labour market in the Baltic States. Inzinerine Ekonomika-Engineering Economics (3):41-48.

Meng, X. 1998. Gender occupational segregation and its impact on the gender wage differential among rural-urban migrants: A Chinese case study. Applied Economics 30(6):741-752.

Meng, X., and J.S. Zhang. 2001. The two-tier labor market in urban China: Occupational segregation and wage differentials between urban residents and rural migrants in Shanghai. Journal of Comparative Economics 29(3):485-504.

Mincer, J. 1958. Investment in human-capital and personal income-distribution. Journal of Political Economy 66(4):281-302.

1970. Distribution of labor incomes: Survey with special reference to human capital approach. Journal of Economic Literature 8(1):1-26.

Mitra, A. 2010. Migration, livelihood and well-being: Evidence from Indian city slums. Urban Studies 47(7):1371-1390.

Mody, A., and F.Y. Wang. 1997. Explaining industrial growth in coastal China: Economic reforms ... and what else? World Bank Economic Review 11(2):293-325.

Mouw, T. 2003. Social capital and finding a job: Do contacts matter? American Sociological Review 68:868898.

Ouyang, P.M., and S.H. Fu. 2012. Economic growth, local industrial development and inter-regional spillovers from foreign direct investment: Evidence from China. China Economic Review 23(2):445460.

Palmer, N.A., D.D. Perkins, and Q. Xu. 2011. Social capital and community participation among migrant workers in China. Journal of Community Psychology 39(1):89-105. 
Yu et al.: Geographic structure of the migrant labour market in China

Pekkala, S. 2003. Migration flows in Finland: Regional differences in migration determinants and migrant types. International Regional Science Review 26(4):466-482.

Plane, D.A., and G.F. Mulligan. 1997. Measuring spatial focusing in a migration system. Demography 34(2):251-262.

Rogers, A., and S. Sweeney. 1998. Measuring the spatial focus of migration patterns. Professional Geographer 50(2):232-242.

Ryan, L., R. Sales, M. Tilki, and B. Siara. 2008. Social networks, social support and social capital: The experiences of recent Polish migrants in London. Sociology-the Journal of the British Sociological Association 42(4):672-690.

Shah, N.M., and I. Menon. 1999. Chain migration through the social network: Experience of labour migrants in Kuwait. International Migration 37(2):361-382.

Shaver, J.M., and F. Flyer. 2000. Agglomeration economies, firm heterogeneity, and foreign direct investment in the United States. Strategic Management Journal 21(12):1175-1193.

Shen, J.F. 2013. Increasing internal migration in China from 1985 to 2005: Institutional versus economic drivers. Habitat International 39:1-7.

Stambol, L.S., N.M. Stolen, and T. Avitsland. 1998. Regional analyses of labor markets and demography: A model based Norwegian example. Papers in Regional Science 77(1):37-62.

Storper, M., and A.J. Scott. 2009. Rethinking human capital, creativity and urban growth. Journal of Economic Geography 9(2):147-167.

Wang, M.Y., and J.P. Wu. 2010. Migrant workers in the urban labour market of Shenzhen, China. Environment and Planning A 42(6):1457-1475.

Xie, G. 2007. Migrant Workers and Urban Labor Market (in Chinese). Sociological Studies 5:22-24.

Xie, Y., and E. Hannum. 1996. Regional variation in earnings inequality in reform-era urban China. American Journal of Sociology 101(4):950-992.

Xu, W., K.C. Tan, and G.X. Wang. 2006. Segmented local labor markets in postreform China: Gender earnings inequality in the case of two towns in Zhejiang province. Environment and Planning $A$ 38(1):85-109.

Yan, S.P. 1990. The movement of labor in Chinese rural-areas - with a focus on developed regions. Developing Economies 28(4):524-543.

Yang, J., and W. Che. 2003. The social nets influence and countermeasures of the work force market in the process of China's transforming (in Chinese). Journal of Hunan Economic Management College 14(4):25-32.

Yang, J., and Z. Jiang. 2008. Advantage or disadvantage? Situation and Development of the new generation of migrant workers (in Chinese). Southern Population 133(2):23-26.

Yang, X., and F. Guo. 1999. Gender differences in determinants of temporary labor migration in China: A multilevel analysis. International Migration Review 33(4):929-953.

Yue, Z., S. Li, M.W. Feldman, and H. Du. 2009. Wandering at crossroad:a comparative study on development will of two generations of migrant rural workers (in Chinese). Population \& Economics 6:58-66. 
Yue, Z., S. Li, X. Jin, and M.W. Feldman. 2013. The role of social networks in the integration of Chinese rural-urban migrants: A migrant-resident tie perspective. Urban Studies 50(9):1704-1723.

Yueh, L.Y. 2008. Do social networks increase labour supply elasticity? Applied Economics Letters 15(1):510.

Zang, L., and F. Pan. 2011. The composition and function of social network for new generation migrants: Example from Hangzhou (in Chinese). Economic Research Guide 34:23-25.

Zhan, S.H. 2011. What determines migrant workers' life chances in contemporary China? Hukou, social exclusion, and the market. Modern China 37(3):243-285.

Zhang, J. 2012. The hukou system as China's main regulatory framework for temporary rural-urban migration and its recent changes. Erde 143(3):233-247.

Zhang, L., and L. Tao. 2012. Barriers to the acquisition of urban hukou in Chinese cities. Environment and Planning A 44(12):2883-2900.

Zhao, Y.H. 1999. Labor migration and earnings differences: The case of rural China Economic. Development and Cultural Change 47:767-782.

Zhao, Z. 2005. Migration, labor market flexibility, and wage determination in China: A review. Developing Economies 43(2):285-312.

Zhu, Y. 2007. China floating population and their settlement intention in the cities: Beyond hukou reform. Habitat International 31(01):65-76.

Zhuang, M. 2009. The social support network for rural migrant workers in Chengdu, China: Local governance and civil society in the fight against poverty and exclusion. IDS Bulletin-Institute of Development Studies 40(6):41-49. 